\title{
Trends and features of socio-economic development of the Kaliningrad region
}

\author{
Albert G. Mnatsakanyan, \\ Doctor of Economics, Professor, \\ Director of the Institute of Industrial \\ Economics and Management, \\ Kaliningrad Technical University \\ Kaliningrad, Russia
}

\author{
Vladimir I. Kuzin, \\ $\mathrm{PhD}$ in Economics, \\ Associate Professor, \\ Institute of Industrial Economics and Management, \\ Kaliningrad Technical University, \\ Kaliningrad, Russia
}

\begin{abstract}
For more than 25 years the Kaliningrad region has a special legal regime for economic activity. The purpose of its implementation was to stabilize and accelerate the socioeconomic development of this exclave Russian region being in difficult geo-economic conditions. The article analyzes tendencies and reveals the main features of the Kaliningrad region. The assessment of the effectiveness of the economic development model implemented in the region is made in the article.
\end{abstract}

Keywords: social and economic development, economic growth, Kaliningrad region, special economic zone

\section{INTRODUCTION, PURPOSE AND OBJECTIVES OF THE RESEARCH}

Considering regional development, it is necessary to understand that in most cases economic growth indicators are used as development criteria [5]. However, growth is not a complete synonym for development, but can only act as one of its indicators. It should be understood that the development of the region is a complex process, requiring the study of its key manifestations and factors. The purpose of the article is to analyze the socio-economic situation of the Kaliningrad region in order to make a conclusion about the effectiveness of the economic development model implemented in the region. To achieve the goal, it is necessary to solve the problems of identifying the main factors that determine development, as well as assessing the impact and degree of influence on the socio-economic development of the region.

\section{METHODS}

Within the framework of studies of the exclave region development we implemented a systematic approach to the factors determining the trends in the socioeconomic situation in the federal subject. At the same time, historical and logical methods were used to analyze the observed indicators characterizing development. The statistical data was analyzed for the period from 1998 to 2015. The impact of factors on the actual final consumption of some households and a comparison of this indicator for the region and for Russia was assessed in the analysis. When choosing research methods, we took into account the shortcomings in methods based on technical analysis approaches of the national accounts system indicators [1].
The set of research methods used is conservative, which makes it possible to compare the results of the study with similar studies conducted earlier, as well as in ones in other regions.

\section{RESULTS}

Assessing the development of the Kaliningrad region of the Russian Federation, first of all, the factors of its economic and geographical situation are singled out. In this point of view, the region is usually regarded as an exclave, separated from other regions of Russia by the territories of foreign states. The consequence of this position of the Kaliningrad region is that the economic distance to other Russian regions is much longer than the geographical one, since the transit of goods between the regions is carried out through Lithuania and Belarus which is more expensive than transportation within Russia.

The second important factor in the socio-economic development of the Kaliningrad region is the regime of a special economic zone that has become very specific to the region. In accordance with the legislation, the special economic zone covers the entire territory of the region where a special legal regime of economic, production, investment and other activities is applied. The free customs zone procedure was applied as well [8].

It should be noted that the high openness of the economy makes the Kaliningrad region highly dependent on allRussian and global factors. So, the situation in the regional economy was significantly influenced by the global economic crisis, the main manifestations of which affected the economic indicators of the region in 2009 and 2010. The regional economy also suffered significantly from the slowdown in Russia's economic development in 2012-2017. Factors that significantly influenced the economic situation in the region were the sanctions imposed by a number of Western countries against Russia in 2014, as well as the Russian government's protective economic measures, which seriously changed the geography of supplies of raw materials for processing. It should be clarified that the location of the Kaliningrad region on the shores of the Baltic Sea, within the territory of the European Union, stipulates simple logistics of goods purchased in neighboring countries. This feature makes the close ties of Kaliningrad enterprises with the companies of nearby countries economically advantageous. Restrictions on the 
supply of goods from these countries led to an increase in logistics costs and significantly affected the economy of many enterprises in the region.

The dynamics of the GRP of the Kaliningrad region since the mid-1990s and to the present time more or less followed Russian trajectory, although it had noticeably less stability. The main drivers of the growth of the Kaliningrad economy in these years were the newly created importsubstituting industries based on the preferences of the special economic zone. Therefore, an important factor in the growth of the region's economy is investment. In investments, a large role is played by the banking system, which is well developed in the region [2]. Studies indicate that in the period 2005-2009. (the stage of the most intensive development of the Kaliningrad SEZ), the Kaliningrad region actual investments volumes in fixed capital significantly (by more than 20\%) exceeded the values of the hypothetical "average Russian region" - an analog of the Kaliningrad region [9].

A criterion that explicitly reflects the role of investment in the structure of social reproduction can be the index of the share of investment in fixed assets in GRP (gross fixed capital formation). Particular attention to this indicator is determined by the general opinion that an increase in the share of investment expenditures in the structure of produced and used GRP leads to the stimulation of the economic development of the region and, subsequently, to a new increase in GRP [1]. During the 2000s, the region experienced a rapid growth in the share of capital investment in GRP. Its maximum - almost $40 \%$ - this figure reached in 2008, after which it began to decline to about the average Russian level. Despite quite substantial preferences for investors, Kaliningrad is currently takes the $47^{\text {th }}$ place among the Russian regions in terms of investment in fixed assets per capita [10].

A major source of investment for the whole observed period was the budgets of all levels. At the same time, budgetary resources were contained not only in the government investment plans, but also in targeted programs implemented in the region [6]. This is one of the main levers of State to manage the economy [3].

Another factor that influenced the industrial growth in the region in the 2000s besides the large-scale investments was a noticeable increase in the effective demand of the population and organizations of Russia. The pace of development of the Kaliningrad industry in these years is impressive. With an average annual growth rate of industrial production across the country at large from 1996 to 2016 equal to $2.5 \%$ and in the North-West Federal District 2.6\%, industrial output in the Kaliningrad region grew by $9.3 \%$ per year. Particularly successful for the Kaliningrad industry were 2004-2006, when industrial production in the region grew more than 4 times, as well as in 2011, when the index of industrial production exceeded $150 \%$. However, the regional GRP growth in the same year was only $4.6 \%$. This shows that the growth in industrial production was not accompanied by the same increase in added value.
At the same time, the lack of available sources to cover expenses for local problems became a serious factor that influenced the development of the Kaliningrad region, which affected the financial and investment potential of the municipal entities of the region and increased the pressure on the regional budget [4].

The main driver of the Kaliningrad industry is importsubstituting production - food industry enterprises and various assembly plants. The products they produce are mostly exported to other regions of Russia. Only for the period from 2000 to 2010 the volume of industrial products produced in the Kaliningrad special economic zone and exported to the rest of Russia increased 15 times. For certain types of goods (TVs, household appliances, cars, fish and canned meat, etc.), the region was a leader in Russia.

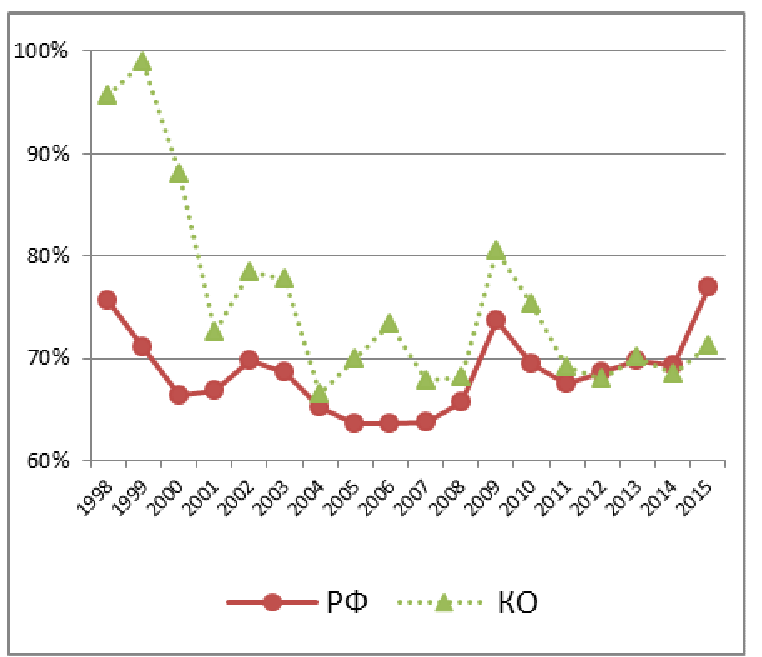

Figure 1. The share of final consumption of households in Russia's GDP and GRP of the Kaliningrad Region

Within the entire period of operation of the Kaliningrad region in the free customs zone regime, there were constant discussions about the nature of the economy, formed under its influence. At the heart of this discussion there was the question if the customs privileges that caused such a significant increase in the production of certain types of goods are justified and lead to an increase in public welfare. In this regard, it is interesting to examine the Kaliningrad economy in terms of the ratio between the GRP per capita and the actual final consumption of households. This analytical indicator, based on official statistical indicators, allows to determine the real role of the region in the economic development of the country - what part of the added value created in the region is not consumed for domestic current needs, but exported to other regions of the country or accumulated in the form of national wealth.

According to the figures of this indicator, in the 1990s early 2000s a significant part (about $90 \%$ ) of GRP created in the region was consumed domestically. However till 2012 the share of final consumption in the Kaliningrad region was higher than the average in Russia. 


\section{CONCLUSIONS AND PERSPECTIVES OF THE LINE OF RESEARCH DEVELOPMENT}

The factor influencing the final consumption is the income of the population. This factor is in turn the result of a combination of demographic factors and factors characterizing the economic development of the territory.

Despite the fact that in some years (2005-2007) the real incomes of the region's population were ahead of the average Russian level, during the last few years there has been a negative dynamics of this indicator. As a result, in 2015 the region was ranked as the 35th in Russia by the size of nominal incomes of the population, while in 2009 it was the 27 th. While it is necessary to understand that the ranking depends on income of all the regions of Russia.

Thus, the created favorable conditions for management in the Kaliningrad region, namely the SEZ regime, did not lead to the formation of a sustainable development model in the region. Difficulties in the development of the Russian economy in recent years have directly affected the dynamics of the socio-economic development of the Kaliningrad region and have resulted in a reduction in the industrial output, a slowdown in investment activity and a decrease in real disposable incomes of the population.

All this suggests the need to continue research the factors that determine regional development and the expansion of such a research at the interregional level.

\section{REFERENCES}

1. Aganbegyan A.G. Investments - the basis for accelerated socio-economic development of Russia // Money and credit. - 2012. - №5. - pp. 10-16.

2. Arunyants G.G., Mnatsakanyan A.G., Sayadyan S.G. Regional banking system as a functional subsystem of the market economy and the factor of development of the real sector of the region's economy // Socio-economic phenomena and processes. 2017. №3.

3. Zuev S.E., Kuzin V.I. Organizational and legal foundations of the system of state and municipal management / S.E. Zuev, V.I. Kuzin, Academy of National Economy under the Government of the Russian Federation. - M.:"Delo" AHX, 2010 p. 118

4. Kokhan A.N. Problems of Forming and Strengthening the Financial and Investment Potential of Municipal Formations / Kokhan A.N. // The Baltic Economic Journal: Scientific and Practical Journal. -2014.- № 1(11) - pp. 2332

5. Kuzin V.I. On the content of the concept of socioeconomic development // The Baltic Economic Journal. 2011. - №2(6). - pp. 123-128.

6. Sergeyev L.I. Efficiency of budgetary resources in conditions of audit of program-target development. // The Baltic Economic Journal - 2015- №1(13). - pp. 69-83.

7. Sergeev L.I., Petrov A.V. Disadvantages of forecasting the economic cycle on the basis of technical analysis of indicators of the system of national accounts. Baltic Economic Journal 2016 - №2 (16), pp. 118-127

8. Federal Law 10.01.2006 No. 16-FZ "On the Special Economic Zone in the Kaliningrad Region and on Amending Certain Legislative Acts of the Russian Federation."

9. Kharin A.G. Investigation of investment features in the Kaliningrad region: sources of financing and evaluation of investors' expectations // Finance and credit.- 2009. №14(350). - pp. 79-82.

10. Kharin AG, Tomkovich A.V. A value approach to assessing the effectiveness of tax incentives for investment (on the example of the SEZ in the Kaliningrad region) // Financial analytics: problems and solutions. - 2013. - №12. - pp. 22-28. 